\title{
Recent advances in valvular heart disease
}

\section{Jenny Rayner* and Bernard Prendergast}

Address: Department of Cardiology, Oxford University Hospitals NHS Trust, Headley Way, Oxford, OX3 9DU, UK

*Corresponding author: Jenny Rayner (jennifer.rayner@ouh.nhs.uk)

Fl000Prime Reports 2013, 5:31 (doi:10.12703/P5-3I)

This is an open-access article distributed under the terms of the Creative Commons Attribution-Non Commercial License (http://creativecommons.org/licenses/by-nc/3.0/legalcode), which permits unrestricted use, distribution, and reproduction in any medium, provided the original work is properly cited. You may not use this work for commercial purposes.

The electronic version of this article is the complete one and can be found at: http://f1000.com/prime/reports/m/5/31

\begin{abstract}
Valvular heart disease is one of the most dynamic and exciting fields in cardiovascular medicine, with significant developments in investigation and management over recent years. In this review, we cover some of the most exciting areas, including the potential for treatment strategies aimed at halting the progression of early aortic stenosis, the use of positron emission tomography in assessing disease activity, novel percutaneous strategies for treating valve disease and new directions in the prevention and management of infective endocarditis.
\end{abstract}

\section{Introduction}

Valvular heart disease has proved one of the fastest moving areas in cardiovascular medicine over recent years, with exciting advances in all areas, including diagnosis and assessment, basic pathophysiology and treatment. This is particularly important, given that valvular heart disease is bound to prove a significant health burden in the future given the burgeoning ageing population and the likely increase in the number of cases resulting from improved diagnostic techniques. In this review, we aim to give the reader a feel for the scope of new developments across multiple fields and provide inspiration for future directions.

\section{Pathophysiology and medical therapy}

Perhaps the most exciting developments in the pathophysiology of valve disease concern aortic stenosis. Aortic stenosis is one of the most common valve diseases in the developed world, and one with significant mortality and morbidity. Almost 10\% of individuals between 80 and 89 years of age have been demonstrated to have aortic stenosis [1], and mortality rates remain high despite recent advances in intervention [2]. Aortic stenosis had long been labelled 'degenerative', implying that it is a passive consequence of wear and tear. However, over the past decade, the underlying process has been found to be complex, involving active inflammatory signalling cascades triggered by endothelial shear stress, as well as progressive fibrosis and calcification [3].

More in-depth understanding of this process raised hopes regarding potential pharmacological strategies to halt the progression of disease. Initially, statins were trialled in hopes of demonstrating the same efficacy as in atherosclerosis. However, three trials failed to demonstrate any effect, except perhaps in very early stages of the disease [4-6]. Research is ongoing into targeting calcium homeostasis directly, aiming to moderate more advanced disease [3].

Improved understanding of the underlying inflammatory processes has, however, allowed steps forward in the assessment of disease activity in its early stages. Positron emission tomography (PET) has been used to demonstrate both calcification and inflammation within the valve, and tracer uptake has been shown to correlate well with severity of stenosis [7]. This is an interesting new strategy that adds to the assessment of the valve, and may permit further study of the disease in its early stages and extent of the response to novel therapies.

\section{Percutaneous treatment of valve disease}

This has been, without doubt, the most exciting and fastmoving change in the field in recent times. Transcatheter aortic valve implantation (TAVI) is becoming widespread, 
and there is a huge volume of research underway to assess the extent of its potential applications. Until recently, patients with symptomatic severe aortic stenosis who were felt to be too high risk for surgery faced a dismal prognosis, often very limited by symptoms such as chest pain, dyspnoea and syncope. The introduction of a bioprosthesis, made from bovine or porcine pericardium and mounted on a stent, which can be deployed across the stenosed valve using a percutaneous approach, has revolutionised the approach to these patients (Fig. 1).

The landmark PARTNER trials assessed the impact of TAVI on not only patients deemed high risk for surgical intervention [8] but also those deemed to be inoperable [9]. These large randomised controlled trials demonstrated that TAVI was equivalent to conventional surgery in high-risk patients in terms of mortality and stroke risk at 2 years. Additionally, mortality in the inoperable group was reduced from $68 \%$ at two years to $43 \%$ - a huge success in this very complex population. There is, however, an increased risk of post-procedural paravalvular regurgitation, which is associated with long-term mortality. The European Society of Cardiology guidelines on valvular heart disease (published in 2012) gave TAVI their full support, stating that its use was indicated in patients with severe symptomatic aortic stenosis deemed unsuitable for traditional surgery, provided that they had been fully assessed by a "heart team" and were likely to gain benefit in terms of quality of life and prognosis [10]. Research is now ongoing into the appropriateness of TAVI in less high-risk patient groups, as well as the use of novel bioprostheses, and techniques to minimise paravalvular leak.

Figure I. The four stages of a transcatheter aortic valve implantation (TAVI)
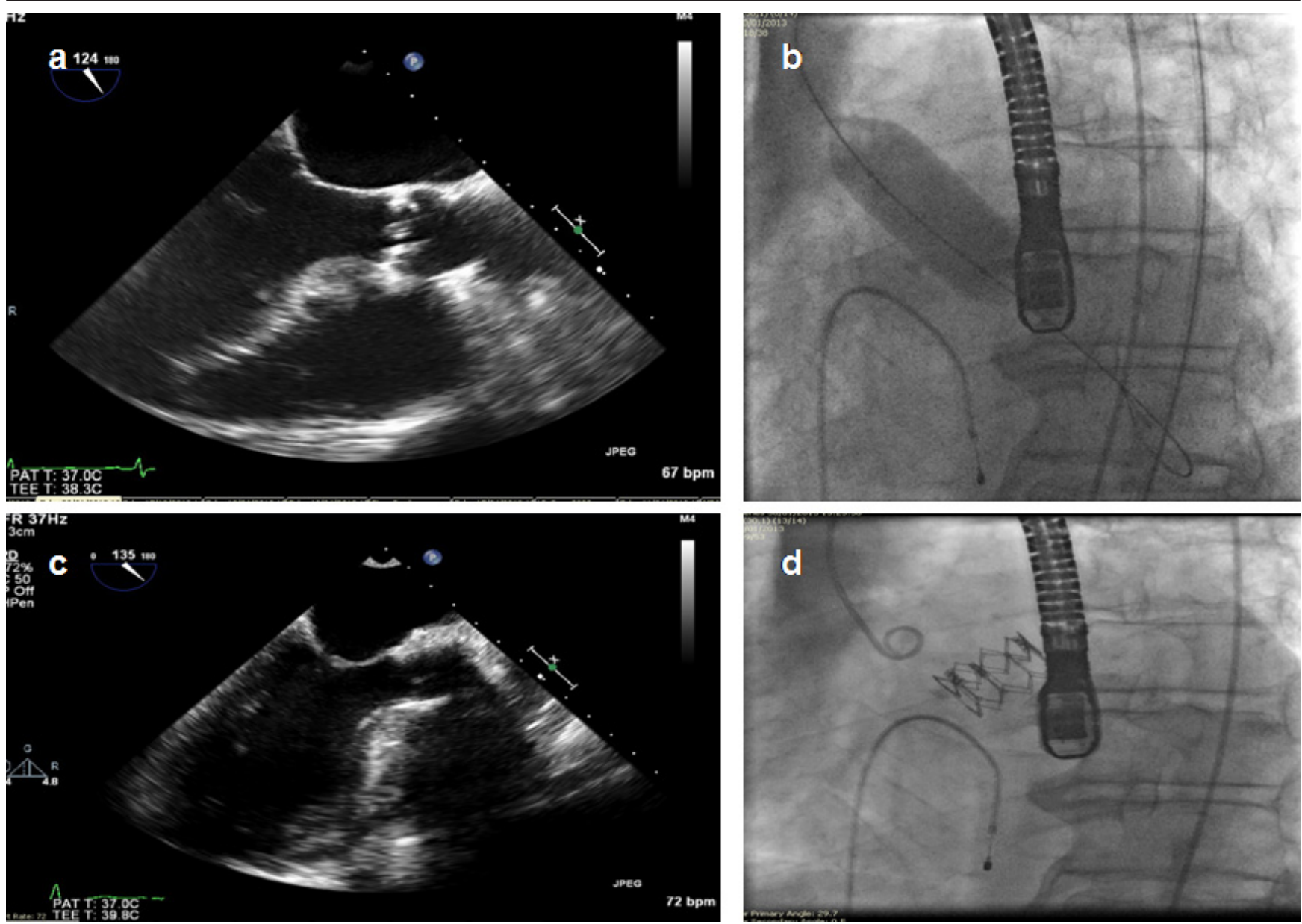

(a) The heavily calcified aortic valve as seen with transoesophageal echo (TOE) (centre right of image); (b) The bioprosthesis balloon inflated, with TOE probe (centre) and temporary pacing wire in right ventricle (lower left); (c) The bioprosthesis deployed on TOE imaging with thin leaflets seen; (d) The residual wire cage mounting the bioprosthesis, with TOE probe (centre), temporary pacing wire (lower left) and catheter in aorta (upper left). 
Although percutaneous intervention in other forms of valve disease has been slower to hit the headlines, balloon valvuloplasty still has a role in mitral stenosis for carefully selected patients, and there is considerable hope that a percutaneous strategy for the treatment of mitral regurgitation may soon become mainstream. The EVEREST II trial examined use of the Mitraclip, a percutaneous clip device used to form an edge-to-edge repair and reduce the severity of mitral regurgitation (Fig. 2). Selected high-risk

Figure 2. The Mitraclip device for percutaneous edge-to-edge mitral valve repair

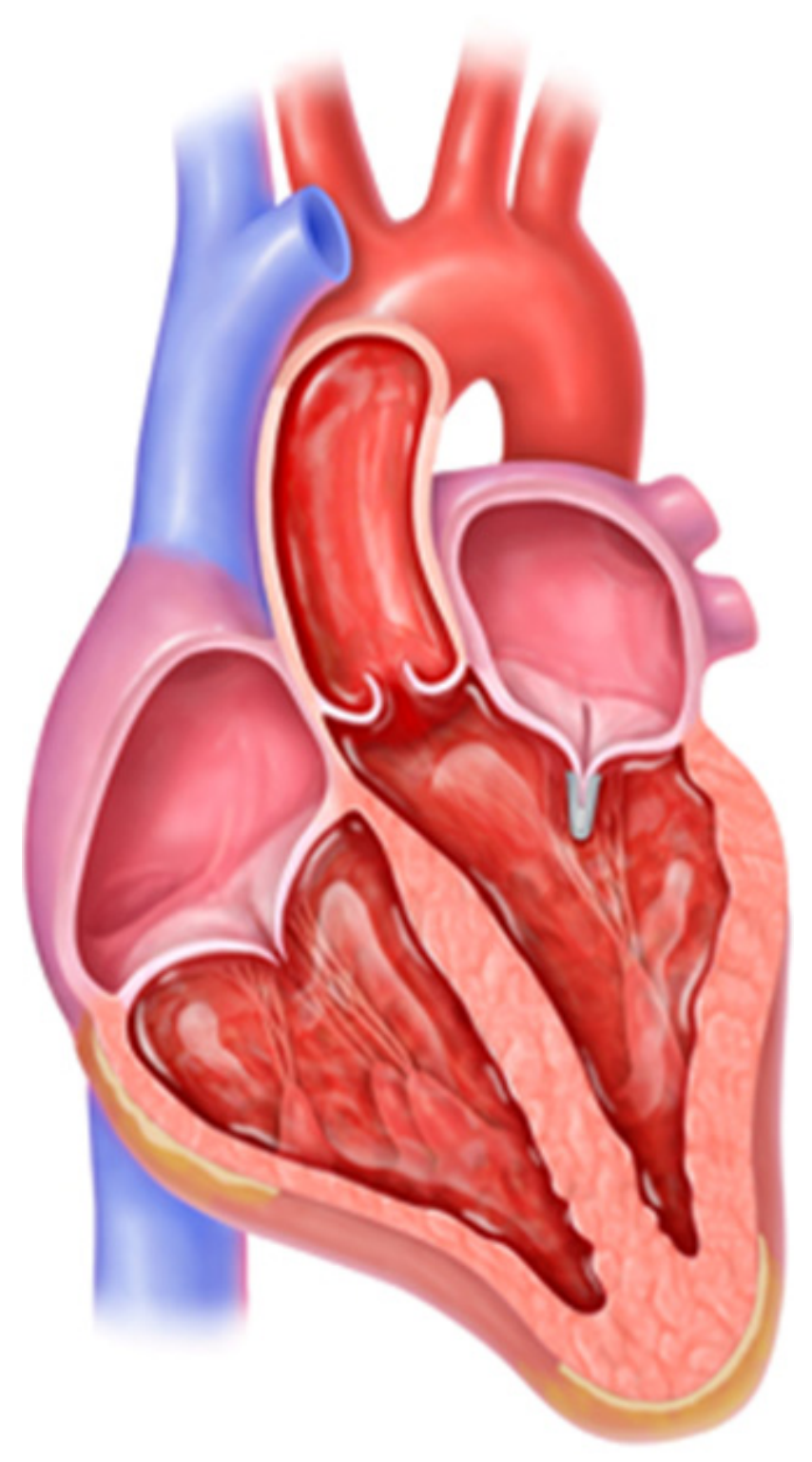

The Mitraclip deployed holding the central parts of the anterior and posterior leaflets of the regurgitant mitral valve together (with thanks to Abbot Vascular). patients with symptomatic severe mitral regurgitation demonstrated improvements in the severity of mitral regurgitation, left ventricular volumes and symptoms and rehospitalisation at 12 months [11].

\section{Infective endocarditis}

There have been various recent changes in protocols for the management of infective endocarditis. Most notable has been the about-turn concerning recommendations for antibiotic prophylaxis, guidelines for which had been in place for decades despite a lack of supporting evidence and the need to treat huge numbers of patients in order to potentially prevent one case [12]. Both the American guidelines in 2007, and subsequently European recommendations in 2009, suggested restricting use of antibiotic prophylaxis to high-risk patients only (those with prosthetic valves, previous endocarditis or complex congenital heart disease). Recent data suggest that these changes have made no impact on the incidence of streptococcal infective endocarditis, though an increase in staphylococcal infective endocarditis has been observed, perhaps related to more patients being exposed to healthcare-associated bacteraemia [13].

Further important evidence supports the role of early surgery in improving the poor outcome of infective endocarditis in a South Korean randomised controlled trial of early vs delayed surgery in patients with large vegetations (Fig. 3 and [14]). The study results were significant in that the incidence of major embolic events was significantly lower in the early surgery group, as were the secondary end-points of heart failure, recurrent infective endocarditis and rehospitalisation. There was no increase in mortality in the group undergoing early surgery. These findings support considering a more aggressive approach to surgery early in the natural history of infective endocarditis as advocated in the 2009 European Society of Cardiology guidelines.

\section{Conclusion}

Of all the fields in cardiovascular medicine, valvular heart disease is possibly the most rapidly changing at the current time. With novel developments in basic science and potential medical therapies, imaging assessment and huge steps in treatment strategies, there is a wealth of new evidence coming to the fore. However, there are still substantial questions that need to be addressed, such as the optimal timing for surgery in mitral regurgitation, the role of TAVI in lower-risk patients, and further study into the impact of early surgery in infective endocarditis.

\section{Abbreviations}

PET, positron emission tomography; TAVI, Transcatheter aortic valve implantation. 
Figure 3. Echocardiographic image of infective endocarditis

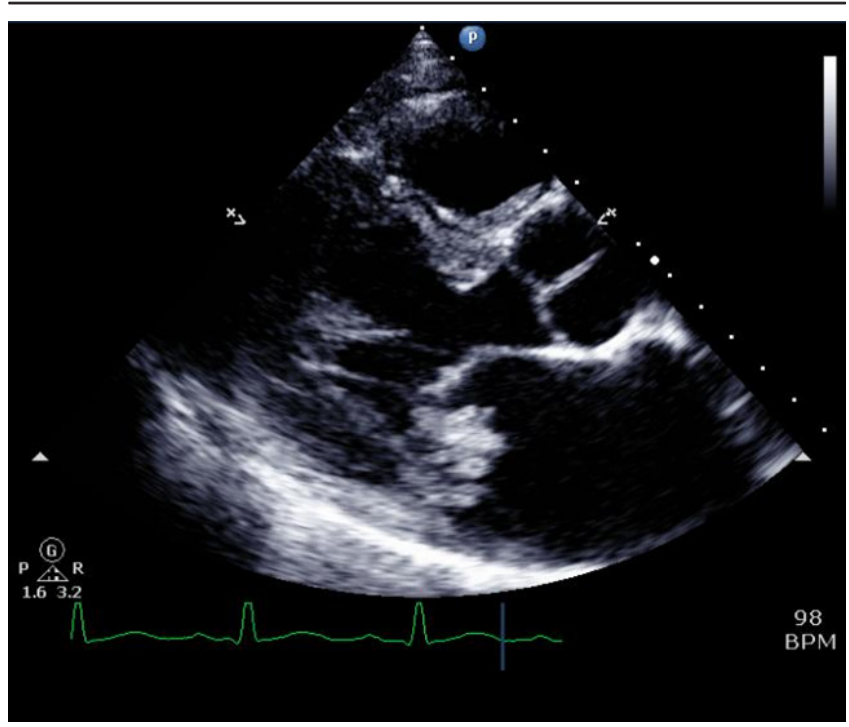

Infective endocarditis affecting the posterior leaflet of the mitral valve, with a large irregular vegetation (lower centre of image) (with thanks to Dr Rizwan Sarwar).

\section{Disclosures}

The authors declare that they have no disclosures.

\section{References}

I. Eveborn GW, Schirmer H, Heggelund G, Lunde P, Rasmussen K: The evolving epidemiology of valvular aortic stenosis. the Tromsø study. Heart 2013, 99:396-400.

\section{FlOOOPrime
RECOMMENDED}

2. Coffey S, Cox B, Williams MJA: The increasing mortality of valvular heart disease. Eur Heart J 20I2, 33(Suppl I):526.

3. Dweck MR, Boon NA, Newby DE: Calcific aortic stenosis: a disease of the valve and the myocardium. J Am Coll Cardiol 2012, 60:1854-63.

\section{FlOOOPrime \\ RECOMMENDED}

4. Cowell SJ, Newby DE, Prescott RJ, Bloomfield P, Reid J, Northridge DB, Boon NA: A randomized trial of intensive lipid-lowering therapy in calcific aortic stenosis. $N$ Engl J Med 2005, 352:2389-97.

\section{FlOOOPrime \\ RECOMMENDED}

5. Rossebø AB, Pedersen TR, Boman K, Brudi P, Chambers JB, Egstrup K, Gerdts E, Gohlke-Bärwolf C, Holme I, Kesäniemi YA, Malbecq W, Nienaber CA, Ray S, Skjaerpe T, Wachtell K, Willenheimer R: Intensive lipid lowering with simvastatin and ezetimibe in aortic stenosis. N Engl J Med 2008, 359:1343-56.

\section{FlOOOPrime}

\section{RECOMMENDED}

6. Chan KL, Teo K, Dumesnil JG, Ni A, Tam J: Effect of Lipid lowering with rosuvastatin on progression of aortic stenosis: results of the aortic stenosis progression observation: measuring effects of rosuvastatin (ASTRONOMER) trial. Circulation 2010, I 2 I:306-14.

\section{FIOOOPrime
RECOMMENDED}

7. Dweck MR, Jones C, Joshi NV, Fletcher AM, Richardson $H$, White A, Marsden M, Pessotto R, Clark JC, Wallace WA, Salter DM, McKillop G, van Beek EJR, Boon NA, Rudd JHF, Newby DE: Assessment of valvular calcification and inflammation by positron emission tomography in patients with aortic stenosis. Circulation 20I2, I25:76-86.

\section{FIOOOPrime
RECOMMENDED}

8. Smith CR, Leon MB, Mack MJ, Miller DC, Moses JW, Svensson LG, Tuzcu EM, Webb JG, Fontana GP, Makkar RR, Williams M, Dewey T, Kapadia S, Babaliaros V, Thourani VH, Corso P, Pichard AD, Bavaria JE, Herrmann HC, Akin JJ, Anderson WN, Wang D, Pocock SJ: Transcatheter versus surgical aortic-valve replacement in high-risk patients. N Engl J Med 20I I, 364:2187-98.

\section{FlOOOPrime
RECOMMENDED}

9. Makkar RR, Fontana GP, Jilaihawi H, Kapadia S, Pichard AD, Douglas PS, Thourani VH, Babaliaros VC, Webb JG, Herrmann HC, Bavaria JE, Kodali S, Brown DL, Bowers B, Dewey TM, Svensson LG, Tuzcu M, Moses JW, Williams MR, Siegel RJ, Akin JJ, Anderson WN, Pocock S, Smith CR, Leon MB: Transcatheter aortic-valve replacement for inoperable severe aortic stenosis. $N$ Engl J Med 2012, 366:1696-704.

\section{FlOOOPrime \\ RECOMMENDED}

10. Vahanian A, Alfieri O, Andreotti F, Antunes MJ, Barón-Esquivias G, Baumgartner H, Borger MA, Carrel TP, Bonis M de, Evangelista A, Falk V, lung B, Lancellotti P, Pierard L, Price S, Schäfers H, Schuler G, Stepinska J, Swedberg K, Takkenberg J, Oppell UO von, Windecker S, Zamorano JL, Zembala M: Guidelines on the management of valvular heart disease (version 20 I2). Eur Heart J 2012, 33:245I-96.

\section{FlOOOPrime}

\section{RECOMMENDED}

II. Whitlow PL, Feldman T, Pedersen WR, Lim DS, Kipperman R, Smalling R, Bajwa T, Herrmann HC, Lasala J, Maddux JT, Tuzcu M, Kapadia S, Trento A, Siegel RJ, Foster E, Glower D, Mauri L, Kar S: Acute and I 2-month results with catheter-based mitral valve leaflet repair: the EVEREST II (Endovascular Valve Edge-toEdge Repair) High Risk Study. J Am Coll Cardiol 2012, 59:130-9.

\section{FlOOOPRime
RECOMMENDED}

12. Habib G, Hoen B, Tornos P, Thuny F, Prendergast B, Vilacosta I, Moreillon P, Jesus Antunes M de, Thilen U, Lekakis J, Lengyel M, Müller L, Naber CK, Nihoyannopoulos P, Moritz A, Zamorano JL: Guidelines on the prevention, diagnosis, and treatment of infective endocarditis (new version 2009): the Task Force on the Prevention, Diagnosis, and Treatment of Infective Endocarditis of the European Society of Cardiology (ESC). Endorsed by the European Society of Clinical Microbiology and Infectious Diseases (ESCMID) and the International Society of Chemotherapy (ISC) for Infection and Cancer. Eur Heart J 2009, 30:2369-4I3.

13. Duval X, Delahaye F, Alla F, Tattevin P, Obadia J, Le Moing V, DocoLecompte T, Celard M, Poyart C, Strady C, Chirouze C, Bes M, Cambau E, lung B, Selton-Suty C, Hoen B: Temporal trends in infective endocarditis in the context of prophylaxis guideline modifications: three successive population-based surveys. J Am Coll Cardiol 2012, 59:1968-76.

\section{FlOOOPRime
RECOMMENDED}

14. Kang D, Kim Y, Kim S, Sun BJ, Kim D, Yun S, Song J, Choo SJ, Chung C, Song J, Lee J, Sohn D: Early surgery versus conventional treatment for infective endocarditis. N Engl J Med 2012, 366:2466-73. 